\title{
Assessment of humoral and cellular immunity induced by the BNT162b2 SARS-CoV-2 vaccine in healthcare workers, elderly people, and immunosuppressed patients with autoimmune disease
}

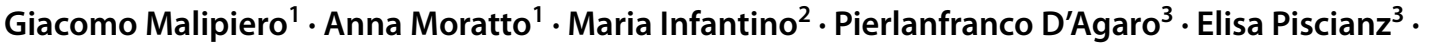 \\ Mariangela Manfredi ${ }^{2} \cdot$ Valentina Grossi $^{2} \cdot$ Enrico Benvenuti $^{4} \cdot$ Matteo Bulgaresi $^{4} \cdot$ Maurizio Benucci $^{5}$. \\ Danilo Villalta ${ }^{1} \mathbb{0}$
}

Received: 22 July 2021 / Accepted: 11 August 2021 / Published online: 21 August 2021

(c) The Author(s), under exclusive licence to Springer Science+Business Media, LLC, part of Springer Nature 2021

\begin{abstract}
The development of vaccines to prevent SARS-CoV-2 infection has mainly relied on the induction of neutralizing antibodies (nAbs) to the Spike protein of SARS-CoV-2, but there is growing evidence that $\mathrm{T}$ cell immune response can contribute to protection as well. In this study, an anti-receptor binding domain (RBD) antibody assay and an INF $\gamma$-release assay (IGRA) were used to detect humoral and cellular responses to the Pfizer-BioNTech BNT162b2 vaccine in three separate cohorts of COVID-19-naïve patients: 108 healthcare workers (HCWs), 15 elderly people, and 5 autoimmune patients treated with immunosuppressive agents. After the second dose of vaccine, the mean values of anti-RBD antibodies (Abs) and INF $\gamma$ were $123.33 \mathrm{U} / \mathrm{mL}$ (range 27.55-464) and $1513 \mathrm{mIU} / \mathrm{mL}$ (range 145-2500) in HCWs and 210.7 U/mL (range 3-500) and 1167 $\mathrm{mIU} / \mathrm{mL}$ (range 83-2500) in elderly people. No correlations between age and immune status were observed. On the contrary, a weak but significant positive correlation was found between INF $\gamma$ and anti-RBD Abs values $(r h o=0.354, p=0.003)$. As to the autoimmune cohort, anti-RBD Abs were not detected in the two patients with absent peripheral CD $19^{+} \mathrm{B}$ cells, despite high INF $\gamma$ levels being observed in all 5 patients after vaccination. Even though the clinical relevance of T cell response has not yet been established as a correlate of vaccine-induced protection, IGRA testing has showed optimal sensitivity and specificity to define vaccine responders, even in patients lacking a cognate antibody response to the vaccine.
\end{abstract}

Keywords Vaccine $\cdot$ INF $\gamma \cdot$ Antibodies $\cdot$ COVID-19 $\cdot$ SARS-CoV-2 $\cdot$ Immunogenicity

\section{Abbreviations}

Abs Antibodies

BAU Binding antibody unit

CLIA Chemiluminescence immunoassay

HCWs Healthcare workers

Danilo Villalta

danilo.villalta@asfo.sanita.fvg.it

1 Immunology and Allergy Unit, Ospedale S-Maria degli Angeli, Pordenone, Italy

2 Immunology and Allergy Laboratory Unit, San Giovanni Di Dio Hospital, Florence, Italy

3 Laboratory for Hygiene and Public Health, University Hospital of Trieste, Trieste, Italy

4 Geriatric Unit Firenze-Empoli, Santa Maria Annunziata Hospital, Florence, Italy

5 Rheumatology Unit, San Giovanni Di Dio Hospital, Florence, Italy
IGRA Interferon gamma release assay

RBD Receptor binding domain

nAbs Neutralizing antibodies

VOC Variants of concern

\section{Introduction}

Vaccine-established herd immunity to SARS-CoV-2 is acknowledged as the straightforward way for controlling the trajectory of the present pandemic. However, effectiveness of vaccines for COVID-19 is hard to predict until results become available from large-scale time-consuming efficacy trials. Therefore, there is an urgent need for both reliable immune correlates of protection and suitable laboratory tools able to measure and to monitor them [1].

The role of Spike-specific nAbs in providing sterilizing immunity has been a natural avenue of investigation at the beginning of the pandemic [2], and induction of nAbs is 
increasingly supported as a valuable surrogate endpoint in vaccine trials [3]. However, evidence is mounting that an early and coordinated $\mathrm{T}$ cell response, not necessarily accompanied by a detectable cognate antibody response $[4$, 5], is associated with less severe COVID-19 [6, 7] in both immune-competent and immune-compromised hosts $[8$, 9] and may provide longer-term protection [10-12], even against variants of concern (VOC) [13, 14]. To which extent these preliminary findings from naturally infected patients may translate into $T$ cell surrogate endpoints of vaccine efficacy is poorly known, but preliminary studies are promising [14-16]. Moreover, cellular assays are both expensive and cumbersome compared to serological ones, even though they may be particularly useful in specific high-risk populations (e.g., humoral immunodeficiency, transplant recipients, neonatal period) [17].

As far as mRNA vaccines are concerned, published peerreviewed trials showed that both mRNA-1273 (Moderna) and BNT162b2 (Pfizer-BioNTech) vaccines elicit Spiketargeted $\mathrm{T}$ cell responses as determined by means of indirect immunological assays such as ELISPOT, intracellular cytokine staining, and activation marker assays, with IFN $\gamma$ emerging as a sensitive marker of responsiveness [18-22]. The diagnostic value of IGRA in COVID-19 has been explored in different cohorts [23,24] and was more recently applied to investigate the persistence of $\mathrm{T}$ cell responses in Austrian patients recovered from SARS-CoV-2 infection [25].

Recently, the diagnostic accuracy of IGRA to detect postvaccination $T$ cell antigen-specific responses was analyzed in a pilot study of 23 randomly selected subjects by Lange et al. [26]. In this study, we aimed at measuring the immunological cellular response to an mRNA-based SARS-CoV-2 vaccine (BNT162b2) by applying IGRA and correlating it to the humoral response in 3 different COVID-19-naïve cohorts: (1) HCWs; (2) elderly people (> 75 years old) from long-term residences; and (3) autoimmune patients on immunosuppressive treatment.

\section{Materials and methods}

\section{Study population}

One hundred and eight consecutive COVID-19-naïve HCWs (mean age, 51; range 23-69; male-to-female ratio, 27/81) receiving the mRNA-based BNT162b2 vaccine (PfizerBioNTech) had their blood drawn at three pre-fixed time points: $\mathrm{T} 0$, first shot of vaccine; $\mathrm{T} 1$, second shot $(+21$ days from $\mathrm{T} 0$ ); and $\mathrm{T} 2,+21$ days from $\mathrm{T} 1$ ( +42 days from $\mathrm{T} 0$ ). Abs assays were performed at $\mathrm{T} 0, \mathrm{~T} 1$, and $\mathrm{T} 2$ and IGRA at $\mathrm{T} 0$ and $\mathrm{T} 2$. HCWs with a history of previous COVID19 , confirmed by positive polymerase chain reaction-based molecular assay for SARS-COV-2 on nasopharyngeal swab, were excluded. No information about comorbidities and concomitant therapy was available.

A cohort of 15 COVID-19-naïve elderly patients randomly selected from a nursing home was enrolled (mean age, 91.8 years; range, 76-99; F/M 15/0). These patients were not affected by immune-mediated systemic diseases and were not on long-term immunosuppressive drugs. An additional limited cohort of five COVID-19-naïve patients affected by autoimmune diseases (four with rheumatoid arthritis and one with pemphigo) on disease-modifying antirheumatic drugs (methotrexate or mycophenolate) plus rituximab were also evaluated. Two of these patients were expressly selected because a validated SARS-CoV-2 serological assay, performed before enrollment, showed absent serological responses to the vaccine. The other three patients were randomly selected for comparison. In the latter two cohorts (elderly people and autoimmune patients), Abs assay and IGRA were performed between 60 and 120 days after the second dose of the vaccine, and peripheral $\mathrm{CD} 19^{+} \mathrm{B}$ cell counting, in the autoimmune cohort only, was performed at the same time of IGRA.

\section{INFY-release assay}

For any single patient, whole blood was collected in lithium heparin tubes, and within $2 \mathrm{~h}$ from venipuncture, five hundred $\mu \mathrm{L}$ each was placed into three separate tubes (Euroimmun, Lübeck, Germany): (1) IGRA TUBE, a stimulation tube coated with components of the S1 domain of SARSCoV-2 Spike protein; (2) IGRA STIM, a stimulation tube coated with mitogen as an aspecific control; and (3) IGRA BLANK, a tube containing no activating components for immune system for the determination of individual background IFN $\gamma$ levels. Plasma was harvested after $24 \mathrm{~h}$ of stimulation at $37^{\circ} \mathrm{C}$ from each tube and evaluated for IFN $\gamma$ levels on an IFN $\gamma$ ELISA plate (Euroimmun, Lübeck, Germany), according to manufacturer's instructions. Briefly, the plate contains microplate strips each with 8 break-off reagent wells coated with a monoclonal anti-IFN $\gamma$ antibody. In the first reaction step, undiluted lyophilized calibrators and plasma samples diluted in sample buffer were added to the coated reagent wells to bind IFN $\gamma$. In two further reaction steps, a biotin-labeled anti-IFN $\gamma$ antibody was added, which was enzymatically detected by means of a streptavidinbound horseradish peroxidase. The resulting color intensity is proportional to the concentration of IFN $\gamma$ antigen in the sample. IFN $\gamma$ concentration was expressed as milli-international units per milliliter $(\mathrm{mIU} / \mathrm{mL})$. The lower detection limit is $3.88 \mathrm{mIU} / \mathrm{mL}$. The results above the concentration of the highest calibrator $(2500 \mathrm{mIU} / \mathrm{mL})$ were considered as equal to $2500 \mathrm{mIU} / \mathrm{mL}$. A patient result was considered valid when IFN $\gamma$ values were $>100 \mathrm{mIU} / \mathrm{mL}$ in IGRA STIM. 
The actual IFN $\gamma$ output for every patient was calculated by subtracting the BLANK value from the respective IGRA TUBE value. Unvalid results were not considered in the final analysis.

\section{Anti-SARS-CoV-2 antibodies}

Anti-SARS-CoV-2 Abs were detected by a quantitative chemiluminescence immunoassay (CLIA) using the RBD of the Spike protein as capture antigen. All samples were processed according to the manufacturer's instruction using an automated CLIA platform (Advia Centaur, XPT, Siemens) with a cutoff level of $1.0 \mathrm{U} / \mathrm{mL}$ for a positive result (sensitivity $96.4 \%$, CI95\% 92.7-98.5\%; specificity $99.9 \%$, CI95\% 99.6-100\%). The conversion factor in binding antibody units (BAU) following the WHO International Standard (NIBCS $20 / 136$ ) is 21.8 .

\section{Peripheral blood immunophenotyping}

CD- $19^{+} \mathrm{B}$ lymphocytes were phenotypically analyzed by bead-based FACS CANTO II (BD Biosciences, San Jose, CA) using a multicolor flow cytometer, with three lasers, blue (488-nm, air-cooled, 20-mW solid state), red (633-nm, 17-mW HeNe), and violet (405-nm, 30-mW solid state). Whole blood was incubated with BD Multitest 6-color TBNK reagent and then lysed with BD FACS ${ }^{\mathrm{TM}}$ lysing solution. Lymphocyte subpopulations were acquired and analyzed with BD FACSCanto clinical software. Immune cells were first gated based on the combination of physical parameters and CD45 expression. The BD Multitest 6-color

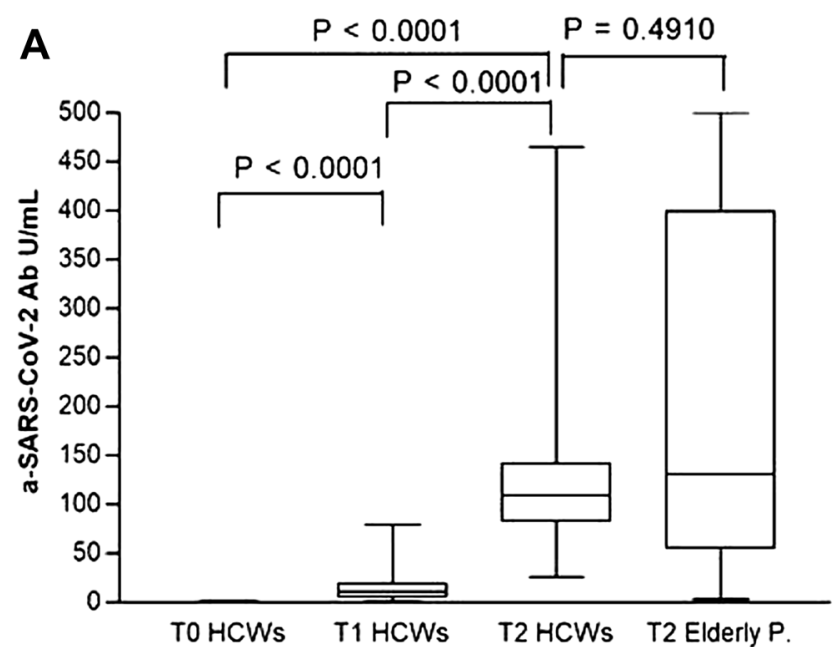

Fig. 1 A Anti-SARS-CoV-2 antibody levels in healthcare workers (HCWs, $n=108$ ) and in elderly people (Elderly P., $n=15$ ). B IFN $\gamma$ levels in HCWs and in elderly people. Blood samples for immunological assays were collected at the time of the first dose of vaccine
TBNK reagent contains antibodies to identify $\mathrm{CD} 19^{+} \mathrm{B}$ lymphocytes.

\section{Statistical analysis}

Statistical analysis was performed by using MedCalc software (Mariakerke; Belgium) and GraphPad (GraphPad Prism 8 XML ProjecT). Comparison of continuous variable was performed using Mann-Whitney $U$ test. Correlation between continuous variables was performed by using Spearman's rho test. A $p$ value less than 0.05 was considered statistically significant. The cutoff of INF $\gamma$ to identify responders to the vaccine was calculated by using Youden index (i.e., cutoff at the highest sum of specificity and sensitivity) from a receiver operating characteristic (ROC) curve analysis.

\section{Ethical issues}

The study was approved by the local ethical committee and assigned the internal protocol number $0342020 \mathrm{H}$ EPIDEMIOLOGIA COVID-19. Informed written consent was required to consecutively enroll patients by physicians. Demographic information was collected at enrollment.

\section{Results}

In the HCW cohort, the mean anti-RBD IgG Abs values at $\mathrm{T} 0, \mathrm{~T} 1$, and $\mathrm{T} 2$ were 0.139 (range 0.00-1.25), 15.02 (range 1.33-71.27), and $123.33 \mathrm{U} / \mathrm{mL}$ (range 27.55-464), respectively (Fig. 1A). Overall, more than $50 \%$ of patients at T2

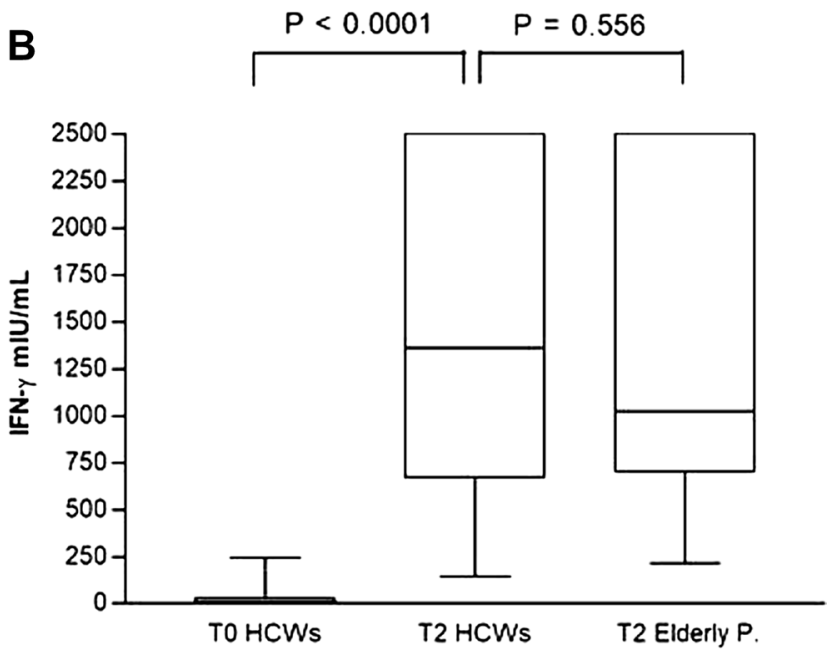

(T0 HCWs), of the second dose (T1 HCWs), and after 21 days from the second dose (T2 HCWs) in HCWs and in between 60 to 120 days after the second dose of vaccine (T2 Elderly P.) in elderly people. Comparisons were performed using Mann-Whitney $U$ test 
had anti-RBD IgG Abs values $\geq 100 \mathrm{U} / \mathrm{mL}$. The mean IFN $\gamma$ responses were $18.10 \mathrm{mIU} / \mathrm{mL}$ (range $0-242.5$ ) at $\mathrm{T} 0$ and $1513 \mathrm{mIU} / \mathrm{mL}$ (range 145-2500) at T2 (Fig. 1B). No unvalid results were obtained. In the elderly cohort (mean age, 91.8; range, 76-99; female-to-male ratio, 15/0), mean anti-RDB IgG Abs and IFN $\gamma$ values were $210.7 \mathrm{U} / \mathrm{mL}$ (range 3-500) and $1167 \mathrm{mIU} / \mathrm{mL}$ (range 83-2500), respectively (Fig. 1A and $\mathrm{B})$.

In the HCW cohort, a ROC curve analysis was performed, and the cutoff for a vaccine-induced IFN $\gamma$ T cell response, calculated by Youden index, was $72 \mathrm{mIU} / \mathrm{mL}$ with a sensitivity of $100 \%$ (CI95\%, 96.5-100\%) and a specificity of 98.9\% (CI95\%, 94.3-99.8\%) (Fig. 2).

To explore the correlation between age and anti-RBD IgG Abs or IFN $\gamma$ values, result values from the cohort of HCWs and elderly patients were joined. No significant correlation between age and Abs concentrations or IFN $\gamma$ levels was found after vaccination (Fig. 3A and B).

When Abs and IFN $\gamma$ levels after vaccination were compared, a weak but significant positive correlation was found: $r h o=0.354, p=0.003$ (Fig. 3C).

In the cohort of rheumatic patients, INF $\gamma$ values were all above $72 \mathrm{mIU} / \mathrm{mL}$, while an Abs response was undetectable in 2 out of 5 patients. In these two patients, the peripheral $\mathrm{CD} 19^{+} \mathrm{B}$ cells were virtually absent (normal range, 200-400

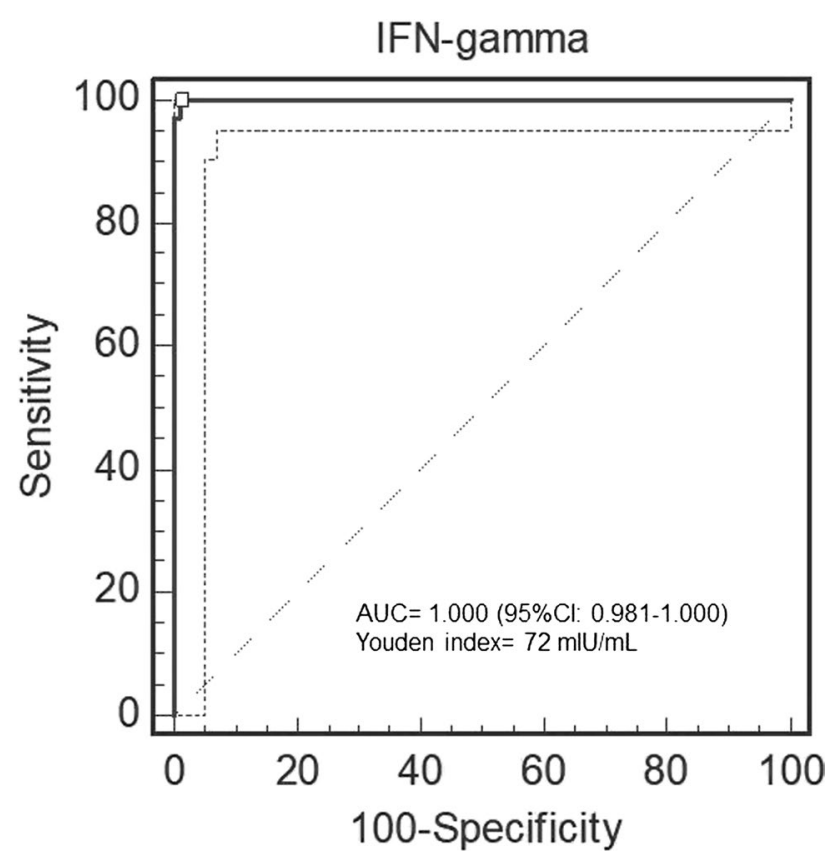

Fig. 2 Receiver operating characteristic (ROC) curve analysis for diagnostic performance of IGRA. The ROC analyzes the ability of IGRA to discriminate INF $\gamma$ response in vaccinated HCWs (T2) versus baseline INF $\gamma$ response (T0) to the Spike antigen of SARSCoV-2.The Youden index (i.e., cutoff at the highest sum of specificity and sensitivity) is $72 \mathrm{mIU} / \mathrm{mL}$. The area under the ROC curve (AUC) is 1.000 (95 CI, 0.981-1.000) cell $/ \mu \mathrm{L}$ ), while INF $\gamma$ levels were $>2500 \mathrm{mIU} / \mathrm{mL}$ (Table 1 ). In the remaining patients, who showed both serological and cellular signs of vaccine immunogenicity, $\mathrm{CD} 19^{+} \mathrm{B}$ cell count was below the normal range but still detectable. Since time from last rituximab administration and the absolute number of rituximab administration may influence $B$ and T cell immune-competency, we also provided this information in Table 1. Anyway, no apparent relationship was found between IFN $\gamma$ or Abs levels and the number of rituximab administrations or the time lapse from last administration.

\section{Discussion}

Besides tuberculosis, analysis of $\mathrm{T}$ cell response has been clinically applied in a very limited number of diseases, namely, cytomegalovirus (CMV) disease in transplant recipients [27] and Toxoplasma congenital disease [28]. T cell responses to SARS-CoV-2 or to vaccines for COVID19 have been widely explored in observational studies and vaccine clinical trials, through techniques that span from direct HLA-tetramer-based immune assays to indirect assays that capture different targets and functional features of $T$ cell activation [29]. Nonetheless, the clinical value of these markers as surrogates for immune protection is difficult to segregate from that of coincidental antibody-related neutralizing immunity [17]. Trying to figure out the most precocious immune correlates of protection induced by vaccination, a group from Singapore prospectively analyzed the development of immune cellular and humoral responses to BNT162b2 from the time of the first jab to the moment when effective immunity was clinically established, i.e., the moment when the rate of infection in the vaccinated group started to separate from that in the placebo group [16]. The authors found that, at this latter time point, a cellular immune response could be detected while neutralizing antibodies could not. A more recent study showed that the presence of a cellular immune response to a Spike-based vaccine was sufficient to confer protection in cancer patients in whom a cognate antibody response was not able to be detected [30]. These proof-of-principle studies suggested that $\mathrm{T}$ cell response is actively involved in early immune protection from SARS-CoV-2 and provided a solid background to introducing $\mathrm{T}$ cell assays in clinical research and eventually in clinical practice. As to IGRA, Lange et al. [26] were the first to provide some evidence on the validity of this assay to define vaccine responsiveness, although in a limited number of 20 healthy individuals. Similarly, in this study, we demonstrated that a standard cohort of COVID19-naïve HCWs exhibited a measurable immune cellular response against the SARS-CoV-2 Spike 1 subunit on IGRA and a cutoff value of $72 \mathrm{mIU} / \mathrm{mL}$ with a $100 \%$ sensibility and $98.9 \%$ specificity could be identified. Not unexpectedly, 

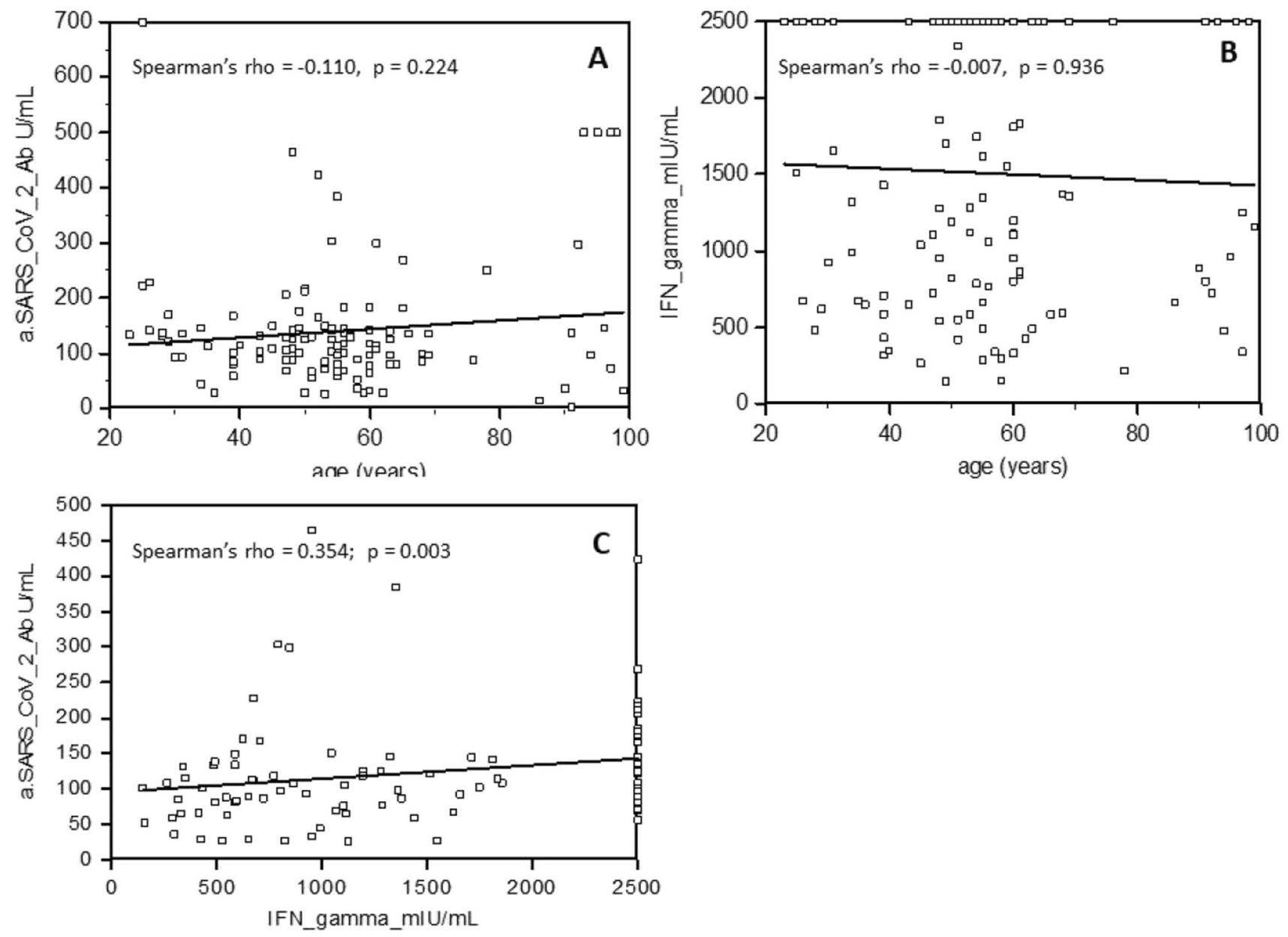

Fig. 3 Correlations between A anti-SARS-CoV2 antibody levels and patients' age; B INF $\gamma$ levels and patients' age; C anti-SARS-CoV2 antibody levels and INFy levels, in joined HCWs and elderly cohorts after the second dose $(n=123)$. Correlations between variables were performed by using Spearman's rho test. The Pearson's coefficient of correlation $(r)$ and the level of significance $(p)$ are indicated
Table 1 Clinical and laboratory characteristics of autoimmune patients

\begin{tabular}{|c|c|c|c|c|c|c|}
\hline Patient & DMARDs & $\begin{array}{l}\text { Weeks from } \\
\text { last rituximab }\end{array}$ & $\begin{array}{l}\mathrm{n}^{\circ} \mathrm{RTX} \\
\text { cycles }\end{array}$ & $\begin{array}{l}\mathrm{CD} 19^{+} \\
(\text {cells } / \mu \mathrm{l})^{\#}\end{array}$ & $\begin{array}{l}\text { Anti-RBD } \\
\operatorname{IgG}(\mathrm{U} / \mathrm{mL})^{*}\end{array}$ & $\mathrm{INF} \gamma(\mathrm{mIU} / \mathrm{mL})^{* *}$ \\
\hline 1. RA & MTX & 37 & 8 & 2 & 0.08 & $>2500$ \\
\hline 2. RA & MTX & 26 & 5 & 3 & 0 & $>2500$ \\
\hline 3. Pemphigo & MYC & 54 & 2 & 36 & 3.4 & 357 \\
\hline 4. RA & MTX & 56 & 9 & 10 & 12.6 & 123 \\
\hline 5. RA & MTX & 36 & 9 & 31 & 282.6 & $>2500$ \\
\hline
\end{tabular}

Legend: $R A$, rheumatoid arthritis; DMARDs, disease-modifying antirheumatic drugs; $M T X$, methotrexate; $M Y C$, mycophenolate mofetil; $R T X$, rituximab. ${ }^{\#} \mathrm{CD}-19-\mathrm{B}$ cell reference range, $200-400$ cells $/ \mu \mathrm{L}$; *anti$\mathrm{RBD} \mathrm{IgG},>1.0 \mathrm{U} / \mathrm{mL}$; positive, ** INF $\gamma>72 \mathrm{mIU} / \mathrm{mL}$. INF $\gamma$ values from IGRA performed between 60 and 120 days after the second dose of vaccine the intensity of $\mathrm{T}$ cell immune response was correlated, although weakly, to RBD-specific Abs titers. Apparently, no correlation between $\mathrm{B}$ and $\mathrm{T}$ cell immune response and age was observed, though it should be pointed out that the timing difference of Abs and IGRA testing in the HCWs and elderly people cohorts makes a definitive conclusion unobtainable. Moreover, the elderly cohort was composed only of females. Sex and gender have been acknowledged to play some role in COVID-19 susceptibility and outcome [31] as well as in susceptibility to vaccine adverse reactions [32]. Nonetheless, we are not aware of a sex-driven difference in vaccine humoral immunogenicity and would not 
consider it a major limitation of the study. Since we lack information on other clinical and anthropometric features of the HCWs population, it was not possible to investigate other potential modulating factors (e.g., obesity). In the additional cohort of 15 elderly individuals, similar results were found although the limited number of patients and lack of clinical information prevented us from running comparisons with the HCW cohort.

Several studies have already shown a reduced humoral immunogenicity of mRNA-based vaccines in acquired immunodeficiency states such as blood cancer [33, 34], endstage renal disease [35], and transplant recipients [35, 36] as well as in patients treated with biological drugs that target discrete pathways of immune function [37, 38]. A number of observations have shown that vaccination against SARSCoV-2 in patients with immune-mediated diseases treated with rituximab can result in the absence of production of Abs to the RBD [39]. A study of 126 patients demonstrated the detrimental effects of rituximab on immunogenicity of vaccines against SARS-CoV-2 [40], and another recent study showed that only patients who had repopulated for B lymphocytes exhibited an immune response to the vaccine against SARS-CoV-2 [41]. Anyway, despite a lacking cognate antibody response, a preserved and detectable $\mathrm{T}$ cell response can still be detected in patients with primary [42] or secondary immunodeficiency, i.e., end-stage renal disease patients on dialysis [43], kidney transplant recipients [44], and patients affected by rheumatic disease on CD20 depleting therapies $[45,46]$. Although limited by the very small number of patients, this study provided further evidence that patients treated with immunosuppressive agents and rituximab can show a strong $T$ cell Spike-specific immune response not accompanied by anti-RBD IgG Abs production when the vaccine was provided at times of low/absent CD19+ B cell counts. Even though reassuring from an immunological prospective, it is doubtful that, in the absence of nAbs, vaccine-induced T cell immunity can by itself provide full protection from SARS-CoV-2 infection (i.e., sterilizing immunity), and presently, our opinion is that vaccine administration should be postponed until B cell repopulation. Pending data demonstrate that the correct timing for vaccination in rituximab-treated patients with rheumatoid arthritis is 9 months after treatment, but data are needed to validate whether peripheral $\mathrm{CD} 19^{+} \mathrm{B}$ cell monitoring might help individualizing this time point [47].

Some limitations of IGRA applicability deserve further attention. The $\mathrm{T}$ cell response to a pathogen is multi-layered, and different subpopulations of cells and molecular pathways can be elicited by natural or vaccine-induced stimulation of $\mathrm{T}$ cells. This is mirrored by different profiles of cytokine functional expression and clinical outcomes [48]. Even though IFN $\gamma$ is one of the main cytokines associated with adaptive immune response to SARS-CoV-2, it cannot be excluded that activation of $\mathrm{T}$ cells expressing other cytokines or activation markers (i.e., co-stimulatory or coinhibitory molecules) might better predict vaccine-induced or naturally acquired protection. For example, it is known from vaccine trials that IL-2 producing $\mathrm{T}$ cells consistently dominated over IFN $\gamma$ producing T cells in many of the experimental cohorts of patients [18, 19]. IGRA, which uses IFN $\gamma$ as the only read-out, might thus not completely reflect the protection conferred by vaccination [49]. It cannot be excluded that IFN $\gamma$ could also foster a maladaptive immune response in severe COVID-19 and it is not known whether, in the absence of humoral sterilizing immunity, an excessive IFN $\gamma$ release primed by vaccination might be associated with worst clinical outcomes in case of breakthrough SARS-CoV-2 infections by the original strains or by more pathogenic variants. For all these reasons, human IFN $\gamma$ release assays are still mainly used for research, and their value in the real life scenario will continue to be investigated before being used for diagnostic purposes [50].

In summary, IGRA has proved to be a reliable laboratory assay to study the cellular immune response to the PfizerBioNTech mRNA-based vaccine, especially in high-risk patients in whom antibody response is undetectable due to acquired humoral immune deficiency. More studies are needed to validate its use as a marker of vaccine responsiveness and disease protection in clinical practice and vaccine trials.

Acknowledgements We thank doctors Del Bianco Francesco, Turchetto Daniela, and Lussi Stefania for sample collection and patients' enrollment.

Author contribution GM, DV, MI, and DP significantly contributed to the drafting of the manuscript and of figures and table, critical analysis of the final draft of the manuscript, and data analysis. AM significantly contributed to sample collection and analysis.

Data availability The datasets used and/or analyzed during the current study are available from the corresponding author on reasonable request.

\section{Declarations}

Ethics approval All procedures performed in studies involving human participants were in accordance with the ethical standards of the institutional and/or national research committee and with the 1964 Helsinki Declaration and its later amendments or comparable ethical standards. The study was approved by the local ethics committee and assigned the internal protocol number 034 2020H EPIDEMIOLOGIA COVID-19.

Consent to participate Informed consent was obtained from all individual participants included in the study.

Consent for publication Patients provided informed consent regarding publishing their data.

Conflict of interest The authors declare no competing interests. 


\section{References}

1. Jin P, Li J, Pan H, Wu Y, Zhu F. Immunological surrogate endpoints of COVID-2019 vaccines: the evidence we have versus the evidence we need. Signal Transduct Target Ther. 2021;6(1):48.

2. Addetia A, Crawford KHD, Dingens A, Zhu H, Roychoudhury P, Huang ML, et al. Neutralizing antibodies correlate with protection from SARS-CoV-2 in humans during a fishery vessel outbreak with a high attack rate. J Clin Microbiol. 2020;58(11):e02107-e2120.

3. Khoury DS, Cromer D, Reynaldi A, Schlub TE, Wheatley AK, Juno JA, et al. Neutralizing antibody levels are highly predictive of immune protection from symptomatic SARS-CoV-2 infection. Nat Med. 2021;27(7):1205-11.

4. Schwarzkopf S, Krawczyk A, Knop D, Klump H, Heinold A, Heinemann FM, et al. Cellular immunity in COVID-19 convalescents with PCR-confirmed infection but with undetectable SARS-CoV-2-specific IgG. Emerg Infect Dis. 2021;27(1).

5. Wang Z, Yang X, Zhong J, Zhou Y, Tang Z, Zhou H, et al. Exposure to SARS-CoV-2 generates T-cell memory in the absence of a detectable viral infection. Nat Commun. 2021;12(1):1724.

6. Tan AT, Linster M, Tan CW, Le Bert N, Chia WN, Kunasegaran $\mathrm{K}$, et al. Early induction of functional SARS-CoV-2-specific T cells associates with rapid viral clearance and mild disease in COVID-19 patients. Cell Rep. 2021;34(6):108728.

7. Sattler A, Angermair S, Stockmann H, Heim KM, Khadzhynov $\mathrm{D}$, Treskatsch S, et al. SARS-CoV-2-specific T cell responses and correlations with COVID-19 patient predisposition. J Clin Invest. 2020;130(12):6477-89.

8. Huang A, Bange E, Han N, Wileyto EP, Kim J, Gouma S, et al. CD8 T cells compensate for impaired humoral immunity in COVID-19 patients with hematologic cancer. Res Sq. 2021 Feb 2:rs.3.rs-162289.

9. Gupta S, Su H, Narsai T, Agrawal S. SARS-CoV-2-associated T-cell responses in the presence of humoral immunodeficiency. Int Arch Allergy Immunol. 2021;182(3):195-209.

10. Asgar Ansari A, Arya R, Sachan S, Jha SN, Kalia A, Lall A, et al. Immune memory in mild COVID-19 patients and unexposed donors reveals persistent $\mathrm{T}$ cell responses after SARSCoV-2 Infection. Front Immunol. 2021;12:636768.

11. Bonifacius A, Tischer-Zimmermann S, Dragon AC, Gussarow D, Vogel A, Krettek U, et al. COVID-19 immune signatures reveal stable antiviral $\mathrm{T}$ cell function despite declining humoral responses. Immunity. 2021;54(2):340-354.e6.

12. Dan JM, Mateus J, Kato Y, Hastie KM, Yu ED, Faliti CE, e al, . Immunological memory to SARS-CoV-2 assessed for up to 8 months after infection. Science. 2021;371(6529):eabf4063.

13. Redd AD, Nardin A, Kared H, Bloch EM, Pekosz A, Laeyendecker O, et al. CD8+ T cell responses in COVID-19 convalescent individuals target conserved epitopes from multiple prominent SARS-CoV-2 circulating variants. Open Forum Infect Dis. 2021; ofab143.

14. Tarke A, Sidney J, Methot N, Zhang Y, Dan JM, Goodwin B, et al. Negligible impact of SARS-CoV-2 variants on $\mathrm{CD}^{+}{ }^{+}$and $\mathrm{CD} 8{ }^{+} \mathrm{T}$ cell reactivity in COVID-19 exposed donors and vaccines. bioRxiv. 2021:2021.02.27.433180.

15. Woldemeskel BA, Garliss CC, Blankson JN. SARS-CoV-2 mRNA vaccines induce broad $\mathrm{CD} 4+\mathrm{T}$ cell responses that recognize SARS-CoV-2 variants and HCoV-NL63. J Clin Invest. 2021;131(10):e149335.

16. Kalimuddin S, Tham CY, Qui M, de Alwis R, Sim JX, Lim JM, et al. Early $\mathrm{T}$ cell and binding antibody responses are associated with Covid-19 RNA vaccine efficacy onset. Med (N Y). 2021. https://doi.org/10.1016/j.medj.2021.04.003.
17. Hellerstein M. What are the roles of antibodies versus a durable, high quality T-cell response in protective immunity against SARSCoV-2? Vaccine X. 2020;6:100076.

18. Anderson EJ, Rouphael NG, Widge AT, Jackson LA, Roberts PC, Makhene M, et al. Safety and immunogenicity of SARSCoV-2 mRNA-1273 vaccine in older adults. N Engl J Med. 2020;383(25):2427-38.

19. Sahin U, Muik A, Derhovanessian E, Vogler I, Kranz LM, Vormehr $\mathrm{M}$, et al. COVID-19 vaccine BNT162b1 elicits human antibody and $\mathrm{T}_{\mathrm{H}} 1 \mathrm{~T}$ cell responses. Nature. 2020;586(7830):594-9.

20. Baden LR, El Sahly HM, Essink B, Kotloff K, Frey S, Novak R, et al. Efficacy and safety of the mRNA-1273 SARS- CoV-2 vaccine. N Engl J Med. 2021;384(5):403-16.

21. Polack FP, Thomas SJ, Kitchin N, Absalon J, Gurtman A, Lockhart S, et al. Safety and efficacy of the BNT162b2 mRNA Covid19 vaccine. N Engl J Med. 2020;383(27):2603-15.

22. Walsh EE, Frenck RW Jr, Falsey AR, Kitchin N, Absalon J, Gurtman A, et al. Safety and immunogenicity of two RNA-based Covid-19 vaccine candidates. N Engl J Med. 2020;383(25):2439-50.

23. Murugesan K, Jagannathan P, Pham TD, Pandey S, Bonilla HF, Jacobson $\mathrm{K}$, et al. Interferon-gamma release assay for accurate detection of SARS-CoV-2 T cell response. Clin Infect Dis. 2020:ciaa1537. https://doi.org/10.1093/cid/ciaa1537.

24. Petrone L, Petruccioli E, Vanini V, Cuzzi G, Najafi Fard S, Alonzi T, et al. A whole blood test to measure SARS-CoV2-specific response in COVID-19 patients. Clin Microbiol Infect. 2021;27(2):286.e7-286.e13.

25. Ladage D, Harzer O,Engel P,Winkler H, Braun RJ. Persisting adaptive immunity to SARS-CoV-2 in Lower Austria. medRxiv. 2021. https://doi.org/10.1101/2021.02.18.21251551

26. Lange A, Borowik A, Bocheńska J, Rossowska J, Jaskuła E. Immune response to COVID-19 mRNA vaccine-a pilot study. Vaccines (Basel). 2021;9(5):488.

27. Deborska-Materkowska D, Perkowska-Ptasinska A, Sadowska A, Gozdowska J, Ciszek M, Serwanska-Swietek M, et al. Diagnostic utility of monitoring cytomegalovirus-specific immunity by QuantiFERON-cytomegalovirus assay in kidney transplant recipients. BMC Infect Dis. 2018;18(1):179.

28. Chapey E, Wallon M, L'Ollivier C, Piarroux R, Peyron F. Place of interferon- $\gamma$ assay for diagnosis of congenital toxoplasmosis. Pediatr Infect Dis J. 2015;34(12):1407-9.

29. Shrotri M, van Schalkwyk MCI, Post N, Eddy D, Huntley C, Leeman $\mathrm{D}$, et al. T cell response to SARS-CoV-2 infection in humans: a systematic review. PLoS One. 2021;16(1):e0245532.

30. Bange EM, Han NA, Wileyto P, Kim JY, Gouma S, Robinson J, et al. CD8+ T cells contribute to survival in patients with COVID19 and hematologic cancer. Nat Med. 2021. https://doi.org/10. 1038/s41591-021-01386-7.

31. Mukherjee S, Pahan K. Is COVID-19 gender-sensitive? J Neuroimmune Pharmacol. 2021;16(1):38-47. https://doi.org/10.1007/ s11481-020-09974-z.

32. Jacobson MA, Zakaria A, Maung Z, Hart C, McCalmont T, Fassett $\mathrm{M}$, Amerson E. Incidence and characteristics of delayed injection site reaction to the mRNA-1273 SARS-CoV2 vaccine (Moderna) in a cohort of hospital employees. Clin Infect Dis. 2021:ciab518. https://doi.org/10.1093/cid/ciab518.

33. Herishanu Y, Avivi I, Aharon A, Shefer G, Levi S, Bronstein $\mathrm{Y}$, et al. Efficacy of the BNT162b2 mRNA COVID-19 vaccine in patients with chronic lymphocytic leukemia. Blood. 2021;137(23):3165-73.

34. Pimpinelli F, Marchesi F, Piaggio G, Giannarelli D, Papa E, Falcucci P, et al. Fifth-week immunogenicity and safety of antiSARS-CoV-2 BNT162b2 vaccine in patients with multiple myeloma and myeloproliferative malignancies on active treatment: 
preliminary data from a single institution. J Hematol Oncol. 2021;14(1):81.

35. Ikizler TA, Coates PT, Rovin BH, Ronco P. Immune response to SARS-CoV-2 infection and vaccination in patients receiving kidney replacement therapy. Kidney Int. 2021;99(6):1275-9.

36. Itzhaki Ben Zadok O, Shaul AA, Ben-Avraham B, Yaari V, Ben Zvi H, Shostak Y, et al. Immunogenicity of the BNT162b2 mRNA vaccine in heart transplant recipients - a prospective cohort study. Eur J Heart Fail. 2021. https://doi.org/10.1002/ejhf.2199.

37. Chavarot N, Ouedrani A, Marion O, Leruez-Ville M, Villain E, Baaziz M, et al. Poor anti-SARS-CoV-2 humoral and T-cell responses after 2 injections of mRNA vaccine in kidney transplant recipients treated with belatacept. Transplantation. 2021. https:// doi.org/10.1097/TP.0000000000003784.

38. Kennedy NA, Lin S, Goodhand JR, Chanchlani N, Hamilton B, Bewshea $\mathrm{C}$, et al. Infliximab is associated with attenuated immunogenicity to BNT162b2 and ChAdOx1 nCoV-19 SARS-CoV-2 vaccines in patients with IBD. Gut. 2021:gutjnl-2021-324789.

39. Connolly CM, Boyarsky BJ, Ruddy JA, Werbel WA, ChristopherStine L, Garonzik-Wang JM, et al. Absence of humoral response after two-dose SARS-CoV-2 messenger RNA vaccination in patients with rheumatic and musculoskeletal diseases: a case series. Ann Intern Med. 2021;25:M21-1451.

40. Boyarsky BJ, Ruddy JA, Connolly CM, Ou MT, Werbel WA, Garonzik-Wang JM, et al. Antibody response to a single dose of SARS-CoV-2 mRNA vaccine in patients with rheumatic and musculoskeletal diseases. Ann Rheum Dis. 2021:annrheumdis-2021-220289.

41. Spiera R, Jinich S, Jannat-Khah D. Rituximab, but not other antirheumatic therapies, is associated with impaired serological response to SARS- CoV-2 vaccination in patients with rheumatic diseases Ann Rheum Dis 2021; annrheumdis-2021-220604.

42. Hagin D, Freund T, Navon M, Halperin T, Adir D, Marom R, et al. Immunogenicity of Pfizer-BioNTech COVID-19 vaccine in patients with inborn errors of immunity. J Allergy Clin Immunol. 2021;:S0091-6749(21):00887-93.

43. Clarke CL, Prendecki M, Dhutia A, Gan J, Edwards C, Prout $\mathrm{V}$, et al. Longevity of SARS-CoV-2 immune responses in hemodialysis patients and protection against reinfection. Kidney Int. 2021;99(6):1470-7.

44. Dolff S, Baotong Z, Korth J, De L, Yang D, Jahn M, et al. Evidence of cell mediated immune response in kidney transplants with negative mRNA-1273 antibody response. Kidney Int. 2021;:S0085-2538(21):00511-21.

45. Bonelli MM, Mrak D, Perkmann T, Haslacher H, Aletaha D. SARS-CoV-2 vaccination in rituximab-treated patients: evidence for impaired humoral but inducible cellular immune response. Ann Rheum Dis. 2021:annrheumdis-2021-220408.

46. Ferguson J, Murugesan K, Banaei N, Liu A. Interferon-gamma release assay testing to assess COVID-19 vaccination response in a SARS-CoV-2 seronegative patient on rituximab: a case report. Int J Infect Dis. 2021;S1201-9712(21):00542-7.

47. Benucci M, Damiani A, Infantino M, Manfredi M, Grossi V, Lari $\mathrm{B}$ et al. Correspondence on "SARS-CoV-2 vaccination in rituximab-treated patients: evidence for impaired humoral but inducible cellular immune response"by Bonelli MM et al. Ann Rheum Dis accepted 2021.

48. Lu LL, Smith MT, Yu KKQ, Luedemann C, Suscovich TJ, Grace PS, et al. IFN- $\gamma$-independent immune markers of mycobacterium tuberculosis exposure. Nat Med. 2019;25(6):977-87.

49. Dolff S, Korth J, Jahn M, Kribben A, Witzke O, Wilde B. AntiSARS-CoV-2 T-cell responses after mRNA vaccination in belatacept treated renal transplant patients. Transplantation. 2021. https://doi.org/10.1097/TP.0000000000003812.

50. Benucci M, Infantino M, Marotto D, Ardizzone S, Manfredi M, Sarzi-Puttini P. Vaccination against SARS-CoV-2 in patients with rheumatic diseases: doubts and perspectives. Clin Exp Rheumatol. 2021;39(1):196-202.

Publisher's note Springer Nature remains neutral with regard to jurisdictional claims in published maps and institutional affiliations. 